\title{
Paid Parental Leave in New Zealand: A Short History and Future Policy Options
}

\author{
Paul Callister and Judith Galtry
}

\section{Introduction}

In early 2005 the Labour-Progressive government stated that, while New Zealand's overall labour force participation rates were high, the rate for some groups of women, particularly those aged 25-34 years, were below the OECD average. Given that this is the main childbearing age range for New Zealand women, mothers of young children form a significant component of this group. There was subsequently much debate about the benefits or otherwise of bringing more mothers into paid work and, inevitably, questions arose about the level of both parental leave and childcare support available to new parents.

Parental leave is a particularly contentious area of public policy. Concerns include health protection for mothers in paid work, equal opportunities for female workers, gender equity in the home, access to adequate antenatal and birthing care, and fertility support. In addition, parental leave debates involve issues around payment, including whether there should be provision for job protection only or for a period of paid leave; who pays for it; the level of payment, including whether there is a 'cap' on the payment; and the length of the payment period. Discussions also often focus on appropriate eligibility criteria for parental leave, including who is considered to be part of a family. Parental leave policy is relevant not only to parents and children, but also to employers, co-workers and the wider society. Given all these potential interest groups, as well as the multiple and sometimes conflicting goals behind various parental/maternity leave policies, it is perhaps not surprising that views about paid parental leave are widely divergent.

Due to the complexity of parental leave considerations, research articles and policy debates often focus on only one aspect of leave. For instance, in the labour market literature there is concern about how 'time out' might affect earnings for women, while the implications for parent-infant bonding and attachment receive little attention. In the health arena, consideration is often given to the optimal length of leave necessary for both recovery from childbirth and breastfeeding, but the effects of leave policies on gender equity concerns do not come to the fore. In this article we argue that health, labour market and gender equity perspectives need to be considered when designing parental leave policies.

This article draws on a number of research papers written by the authors since the early 1990s. ${ }^{1}$ First, it briefly considers historical New Zealand policy debates about parental leave. This discussion identifies themes that continually recur in the debates. Consideration is then given to how paid parental leave policy might develop in the future. This includes a brief discussion as to why there is justification for taxpayers' support for paid parental leave.

\section{A short history of policy developments}

In industrialised nations, the issue of maternity leave has long been a part of debates around 'protective' labour legislation. For example, in 1877 Switzerland passed legislation which restricted women's paid work two weeks before and six weeks after the birth of a child. A number of European countries followed with similar policies. In 1919 the International Labour Organization (ILO) was

1 The main papers and book chapters informing this article include: Galtry, J. and P. Callister (2005) 'Assessing the optimal length of parental leave for child and parental well-being: how can research inform policy?', Journal of Family Issues, 26(2), pp.219-46; Callister, P. (2002) 'Should job protection and income support for new parents be separated? Policy options in a US and New Zealand context', Community, Work \& Family, 5(3), pp.279-99; Galtry, J. (2002) 'Child health: an underplayed variable in parental leave and early childhood education policy debates?', Community, Work \& Family, 3, pp.25778; Galtry, J. and P. Callister, P. (1995) 'Birth and the early months: parental leave and paid work', in Callister, P., V.N. Podmore, J. Galtry and T. Sawicka (eds), Striking a Balance: families, work and early childhood education, Wellington: New Zealand Council for Educational Research, pp.13-66. 
formed. The Maternity Protection Convention (No. 3) was among those policies developed during the first year of the ILO's existence. ${ }^{2}$ This convention 'protected' women's employment, including through provision for a period of paid leave. However, while many European countries subsequently introduced maternity leave policies, including in some cases provision for paid leave, in New Zealand it took until 1948 for some form of leave to be introduced, and then it covered only maternity leave within the public service. ${ }^{3}$

During the 1970s the issues of maternity and parental leave gained prominence in policy debates in New Zealand. This was perhaps not surprising, as it was a decade in which there was a dramatic upsurge in interest in feminist issues, both in New Zealand and overseas. However, other trends, in particular changes in the demand for and supply of labour, also impacted on those debates.

Part of the impetus for these debates came from internationally-inspired events. Throughout industrialised countries the 1975 United Nations International Women's Year provided a focal point for debates about a range of issues affecting women, including matrimonial property and parental leave. As a forerunner to this year, in September 1973 the Labour government in New Zealand set up a select committee on 'Women's Rights'. The committee's findings were published in 1975. This publication covered a wide range of issues, including education, childcare and parental leave. The committee's recommendation on parental leave was that the government (a) introduce legislation for paid maternity leave for employed women with the objective of either (i) ratifying by legislation ILO Convention No. 103 concerning maternity protection, or (ii) giving effect to the principles contained in the convention; and (b) consider the desirability of introducing paid paternity leave in cases of family need.

The Labour government did not act on these recommendations, but in the latter part of 1975 introduced a new concept, that of a child minding allowance to be paid to mothers. This was part of a separate, but related, debate about paying a 'mothers' wage' which was taking place.

The 1975 election manifesto of the opposition National Party indicated that it was not in favour of paid leave.
Reflecting its concerns about business viability, it stated that maternity leave without pay would be available to women for a period of up to 12 weeks, without loss of job security, promotion or superannuation rights, providing this did not cause undue disruption to a business enterprise. The possibility of men needing job 'protection' at the time of a child's birth was also raised.

Despite the undertaking in its manifesto, the new National government elected in November 1975 did not immediately act on its promise to introduce maternity leave. Instead, in 1976 it asked the National Council Advisory Council on the Employment of Women (NACEW) to draw up a series of proposals for protecting women's employment. NACEW argued for a single-rate social security benefit payment for a period of three months from the date of birth, regardless of the mother's marital status, and up to two weeks paternity leave, with a single-rate social security benefit. These recommendations are likely to have reflected other policy issues of the time, including the promotion of universal rather than targeted benefits.

\section{Job protection legislation}

In late 1979 the National government introduced the Maternity Leave and Employment Protection Bill. As indicated by its name, this bill focused on job protection, only covered women, did not include parents who were adopting babies, and had very tight eligibility criteria.

Key issues identified in submissions to the select committee considering the bill included the need to expand the eligibility criteria for leave to include fathers, and to reduce the length of time in paid employment required before a woman could take leave. In the original draft of the bill, female employees had to serve 24 months with an employer and work full time (defined as 35 hours or more per week). A number of women's groups also made the point that parental leave was

2 The International Labour Organization's Maternity Protection Convention was introduced in 1919 (Convention No. 3), revised in 1954 (Convention No. 103), and then again in 2000 (Convention No. 183).

3 This is an example of an employer, the government in this case, offering paid leave. Employers can, and do, offer paid leave to some employees. Estimates of the prevalence of PPL (paid parental leave) funded directly by New Zealand employers prior to the introduction of the 2002 paid leave legislation varied from just $13 \%$ to $43 \%$ of workplaces. Just over a third of employees (35\%) had some form of PPL in their contracts (http://www.eeotrust.org.nz/news/ index.cfm?content id=212). While important, the issue of employerprovided leave is not directly discussed in this article. 
essential if a mother was seriously ill, died or was otherwise unable to care for her child.

A significant number of submissions argued for paid leave, and there was also concern that the bill did not cover adoption. Not surprisingly, unions and women's groups featured prominently in the call for paid leave. While most of the submissions supported the concept of mandated leave, the main opposition to the passing of the legislation came from employers. This is a response seen across most OECD countries.

The submissions to the select committee tended to focus on labour market concerns. Despite maternity leave having been promoted in many countries on the basis of its potential health benefits to women and children, such as promoting breastfeeding, few submissions mentioned these.

While some women's groups considered that the legislation needed major redrafting to be of use to women and, moreover, to not penalise them, it was not opposed outright by them. This is possibly because it was seen as a first step towards more appropriate laws. In contrast, in debates occurring at the same time in the United States, some women's groups opposed bringing in any such 'protective' legislation unless it was completely gender neutral.

After its consideration by the select committee, the bill continued to cover only women. However, the time they had to have served with an employer was reduced to 18 months, while the hours per week required to be eligible for leave were reduced to 15 or more. In addition, women who adopted an infant were now also included in leave coverage. The bill was passed into law in 1980.

With the change of government in 1984, the Labour Party was in a position to change the law. In its 1984 election manifesto it had promised to investigate paid parental leave, and to support unpaid parental leave being available to either parent in heterosexual, twoparent families for a period of up to five years to care for each preschooler, with the right of re-entry into the workforce with any necessary retraining. Subsequently, in 1986 a working party was set up to investigate payment for parental leave. The majority of this group considered that there were strong arguments for a parental leave payment on equal employment opportunity grounds. It was argued that such payments would reduce potential conflicts between paid work and family responsibilities and help ensure adequate infant care. The working party nevertheless concluded that a payment could not be justified at that point in time because the costs would be substantial and payments would be ahead of existing practice in awards and agreements.

\section{Extending job protection}

In late 1986 the Labour government introduced the Parental Leave and Employment Protection Bill. The most significant feature of this bill was the expansion of job protection provisions to include fathers. In addition, it increased the period of extended leave from six months to a year. Finally, in the final legislation the eligibility criteria were reduced to 12 months service and 10 hours to be worked per week.

For those in favour of the legislation three key issues emerged: eligibility to take leave; flexibility in its use; and payment. In terms of eligibility, NACEW and various unions argued that the exclusion of some parttime workers continued to be problematic. While job protection was now being extended to fathers, many of the submissions considered this too narrow in view of changing family and parenting patterns. For example, the Federation of Labour considered that paternity leave should instead be called 'nominated care givers' leave. Again, it was mainly unions who argued for paid leave. The favoured funding system was some variation of the ACC system, with employers, employees and the state sharing the cost.

In 1988 the Royal Commission on Social Policy considered the issue of parental leave. The Commission acknowledged the value of the legislation, but felt there was no logic in imposing an arbitrary level of working hours for entitlement to parental leave and recommended that this restriction in the act be removed. The Commission also recommended that the legislation be extended to cover all primary caregivers.

On the question of paid leave, the Commission agreed with the findings of the 1986 working party that there were strong arguments for payment. It nevertheless concluded that payment for parental leave was only one of a number of strategies required for the attainment of greater equality of opportunity in employment, and, in view of various financial constraints, advised against it at that point in time. 
Instead, the Commission recommended the introduction of a 'carers' allowance' for those engaged in the full-time care of children. This entitlement would be individually assessed and, because of the potentially high cost to taxpayers, would be set at a relatively low level compared with allowances for sole parents. Such a payment was seen as a first step towards paid parental leave.

Despite these changes, there continued to be debate about parental leave, with issues raised in the 1970s still being discussed. In 1993 Alliance MP Laila Harre launched the campaign for 12 weeks paid parental leave. Subsequently, Harre was to become a key force in the introduction of paid leave. The 1994 International Year of the Family provided a focal point for further discussions about parental leave, centring mainly on the issue of paid leave. In the same year the Labour Party published a report on paid leave.

In 1995, under a National government, a further report on parental leave was published by the Ministry of Women's Affairs. This focused on labour market issues. Overall, the study provided evidence of the benefits of parental leave in terms of assisting women to remain attached to their workplace around the birth of a child, as well as providing arguments for introducing paid leave.

In 1998 Harre introduced a private member's bill for 12 weeks paid leave. This bill was referred to select committee, with most submissions supporting the legislation, but it was defeated in Parliament by a narrow vote in 1999 .

Subsequently, the Parental Tax Credit was introduced as part of a wider Family Assistance package outlined in the 1999 Budget. It was available to qualifying families with a child or children born on or after 1 October 1999. The government did not support the provision of European models of paid parental leave, but nevertheless wished to provide some financial support to new parents with low incomes.

\section{The introduction of paid leave}

The context for the re-introduction of paid leave legislation included intense debate in New Zealand in the 1990s about the role of the state, including the influence of employment law on the workings of the labour market. Reducing the role of both the state and unions in the labour market, the Employment Contracts
Act was passed in 1991 by the National government. Subsequently, an incoming Labour government repealed this legislation.

There were other changes in the 1990s that affected the labour market. One was the passing of the Human Rights Act in 1993, with one aim of this legislation being to prevent discrimination in the labour market. A key concern in historical debates about parental leave was that if such leave were made available, employers would discriminate against women of childbearing age.

In 2001 the Labour-Alliance government introduced the Parental Leave and Employment Protection (Paid Parental Leave) Amendment Bill to Parliament. The Alliance party, led by Harre, had made the introduction of paid parental leave legislation a key part of its coalition agreement with Labour. The design of the legislation was strongly influenced by Harre's background in supporting women's and workers' rights. However, the health benefits of parental leave, particularly the potential support for breastfeeding, were focused on far more than in previous parental leave debates.

In the bill, statutory job protection and eligibility for paid leave were linked. Mothers who were eligible under the job protection criteria were to be entitled to 12 weeks paid leave, commencing in July 2002. Mothers could chose to transfer some or all of the leave to their partner provided the latter was also eligible for job protection in his or her own right.

In the final legislation, the allocation of rights to leave for adoptive parents was no longer determined by gender. This was an indication that, for adoptive parents, the care of children, not pregnancy, childbirth or breastfeeding, was a key concern, and it was considered that families themselves, not the government, should determine who took the leave. However, for biological parents the legislation remained the same: i.e. the mother retained the primary entitlement to paid leave. Ironically, this was supported by some women's groups, despite the strength of their earlier arguments for gender-neutral leave. Therefore, from 1 July 2002 biological mothers and a nominated adoptive parent who had been employed by the same employer for at least 10 hours per week over the previous year were eligible for 12 weeks paid parental leave. As a backup to this scheme, the government also announced the extension of the existing tax credit scheme for new families. 
Table 1: Key events leading to the introduction of paid parental leave in New Zealand

\begin{tabular}{|c|c|}
\hline 1919 & $\begin{array}{l}\text { International Labour Organization signed Maternity Protection Convention } \\
\text { (No. 3) }\end{array}$ \\
\hline 1948 & Maternity leave introduced in New Zealand public service \\
\hline 1980 & Maternity Leave and Employment Protection Act \\
\hline 1987 & Parental Leave and Employment Protection Act \\
\hline 1999 & Parental Tax Credit announced in budget \\
\hline $2002 \& 2004$ & $\begin{array}{l}\text { Parental Leave and Employment Protection (Paid Parental Leave) } \\
\text { Amendment Act }\end{array}$ \\
\hline
\end{tabular}

\section{Further incremental change}

Subsequently, the paid parental leave legislation has been reviewed. In these reviews and associated discussions, concerns have centred on both the length of leave and the eligibility criteria. A formal complaint was also lodged with the Human Rights Commission on the grounds that the legislation discriminated against biological fathers, as they did not have an independent right to take a period of paid leave. ${ }^{4}$ These reviews have resulted in the length of leave being changed first to 13 weeks, and then to 14 weeks in December 2005. It is also proposed that from 1 July 2006, 14 weeks paid parental leave be available to self-employed mothers who have been working an average of 10 hours per week during the six months before the birth or adoption of a child (with the same right to transfer to their partners as applies to employees). ${ }^{5}$ This proposal moves eligibility away from being based on job protection, as legislation cannot protect a self-employed position. However, no changes have been proposed to the eligibility criteria for biological fathers.

\section{Future policy options}

In this section, three main issues are considered. First, should paid leave be a universal right rather than being linked to job protection? Second, should there be a further extension of the period of leave and, if so, is there an optimal length of leave? Third, and particularly relevant if the period of leave is extended, should fathers be better supported to take a period of leave?

\section{Why should taxpayers provide paid leave?}

To contextualise these issues, it is first worth considering some of the reasons why governments might step in and mandate job protection and/or for taxpayers to provide some income transfer to new parents. According to the European Commission, there are, potentially, many societal benefits of parental leave. These include the 'promotion of equal opportunities between women and men in the labour market through enabling women to retain their position in the labour market during child-bearing'; the 'improvement of economic performance, through making better use of human resources as a result of retaining women workers in the labour force and enabling parents to work under less stress'; and 'recognising the social importance of motherhood and fatherhood'. 6

The list of benefits set out by the European Commission can be re-grouped into three main categories. These are:

- promotion of gender equity in both the labour market and the home;

- protection and promotion of the physical and psychological health of parents (mainly mothers) and children; and

- maximisation of employment and utilisation of the skills of the workforce.

4 The history and outcome of this complaint can be found at http:// www.fatherandchild.org.nz/submissions.htm.

5 The Parental Leave and Employment Protection (Paid Parental Leave For Self-Employed Persons) Amendment Bill was being considered by select committee in early 2006 .

6 European Commission (1994) Leave Arrangements for Workers with Children: a review of leave arrangements in the member states of the European Community and Austria, Finland, Norway and Sweden, Brussels: European Commission Network on Childcare and other Measures to Reconcile Employment and Family Responsibilities for Women and Men. 
In addition, reducing the conflict between work and family may potentially have a number of beneficial effects on society, including possibly increasing national fertility rates in the face of an ageing population.

It is difficult to quantify many of the potential benefits. For some, such as an increase in fertility, there is mixed evidence as to whether parental leave policies in fact have any influence. While the relationships are difficult to unpick, there is some evidence that paid parental leave has a positive effect on child mortality rates. Some of these possible benefits may be obtained through job protection alone, even if no payment is attached. But payment potentially allows a much larger group to take time out of work and utilise longer periods of leave. It also signifies recognition that some parents might not take a sufficient period of leave if relying on their own financial resources.

\section{Should job protection and eligibility for payment be linked?}

As indicated by past debates about leave policies in $\mathrm{New}$ Zealand, a fundamental question remains as to whether paid leave should be linked to job protection or whether it should either be a universal right, or targeted on the basis of some other criteria such as income. This is a particularly important issue in countries such as New Zealand that have relatively flexible labour markets. OECD surveys have demonstrated that entitlement to both job protection and income support is often conditional on previous work experience undertaken on a continuous and full-time basis, yet contingent and/ or non-standard work is becoming more common in many countries. ${ }^{7}$

If income support is seen as societal recognition that parents lose income from paid work in order to care for children, then there is some reason to link payments to recent work history. This approach potentially recognises that the opportunity costs associated with 'time out' of paid work vary. Higher income parents who have invested heavily in their education and subsequent careers potentially lose more money than lower income parents when they take time out of paid work, so may need to be compensated at a higher rate.

However, there remains a question as to whether all work history should be considered, not just those periods spent in eligible jobs and in eligible time periods.
Alternatively, if parental leave is seen as being a 'workers' right' in the same way as the right to paid holidays and paid sick leave, then payment should also be linked to current earnings, with the time out being set at the same daily rate as would be earned on normal work days. If it is perceived as a workers' right, it should also be the employer, or perhaps employers as a group, who pays, rather than the wider society. However, there are a number of problems with this approach, including that employers may then discriminate against women of childbearing age.

The arguments for basing payment on narrow, employment-related eligibility criteria are substantially undermined when a significant number of potential new parents find themselves in contingent employment, or have a period out of paid work before having a child, sometimes through choice, but often through no fault of their own, and are thus excluded from having the right to job protection, and therefore, in a New Zealand context, to paid leave.

While not all those in contingent or non-standard work are unskilled, low paid workers, this group will suffer the most if ineligible for leave. The current eligibility criteria therefore give rise to concerns about 'middle class capture'. For instance, in the policy agencies that designed parental leave in New Zealand, eligible new parents are often able to claim their statutory entitlement to paid leave while also receiving a period of paid leave from their employer. In contrast, the lower paid contract cleaners who tidy their offices at night are less likely to be supported by their employer when taking a period of parental leave. Depending on their contract, they may also not be eligible for the statutory paid leave scheme.

In contrast, viewing parental leave from a health perspective encourages a de-linking of parental leave payment from a narrow, job-based eligibility criterion. There may well be some health impacts for fathers associated with having a period of leave, such as improved emotional well-being through being able to bond with their infant and having an increased commitment to childcare, even if parents subsequently separate. However, the health literature generally focuses on the impacts on women and children. Having leave

7 Non-standard work is generally seen as not being permanent or full-time. Included in non-standard work are self employment, shortterm contracts and casual work, including seasonal work. 
from paid work can have an impact on pregnancy, recovery from birth, the ability to isolate young infants from possible sources of infection by looking after them at home (a gender-neutral activity), and the ability of mothers to breastfeed their children. While the costs in terms of ill health can be high for individuals, these costs also impact on the wider society through either private health insurance premiums or taxes to support public healthcare programmes. While implicitly understood by policy makers for a long time, the relationship between parental leave policy and child health has only recently been explicitly highlighted in the English-language parental leave literature. The health perspective suggests either targeting paid parental leave based on income or the universal extension of paid leave to all new parents.

\section{Gender equality?}

A key concern for parental leave policy makers relates to the appropriate length of leave, and in particular whether there is an optimal length. As this is bound up with issues of gender equity as well as biological functions, gender will be considered first.

For gender equity to occur both in the labour market and the home, one, or preferably both, of the following needs to take place:
8 A number of recent papers have considered fathers and parental leave, including Carlsen, S. (1998) Men on Parental Leave: how men use parental leave in the Nordic countries, report prepared for the Nordic Council of Ministers.

- Women need to increase their employment tenure and their lifetime hours of paid work and, related to both of these, their yearly and lifetime earnings from paid work.

- Men need to undertake an equal share of childcare and household work. This will generally require a reduction in their paid work hours.

One rationale for providing job protection to women is to keep them attached to the labour market. This will increase their job tenure and, hopefully, their hourly and lifelong earnings relative to men. But in the Nordic countries in particular, policy makers have decided that encouraging fathers to take leave is also a means of achieving greater equality between women and men. The introduction of a special non-transferable 'pappa' month of leave in 1995 in Sweden has been associated with an increase in the time fathers spend on leave (see Box). However, research indicates that this leave is likely to be taken if: ${ }^{8}$

- it is non-transferable to the mother;

- the mother has not resigned from work but has a protected job to return to;

\section{Swedish parental leave}

In Sweden, a couple can take up to 13 months off work between them, with the government paying $80 \%$ of lost wages up to a ceiling. A further 90 days can be taken with a smaller payment. The leave can be used in a block, or taken in batches before the child is eight. However, most of the parental leave is taken during the first two years after the child is born. Sweden was one of the first countries to earmark part of the parental leave for fathers. One 'pappa' month was introduced in 1995 and a second 'pappa' month followed in 2002. There is no government support for out-of-home childcare in the first year of a child's life, but strong support in subsequent years.

While Sweden actively encourages fathers to take a period of paid leave, some other paid leave legislation is, unlike the New Zealand legislation, gender neutral. For example, the Californian Paid Family Leave Law that became effective in mid-2004 is gender neutral. It can be used as a maternity leave, but fathers or adoptive parents can equally use it. It is not the government that determines who has primary rights to take leave, but rather parents themselves.

In Sweden, the fact that two months of paid leave can be set aside specifically for fathers partly reflects the long period of paid leave. This raises the issue of whether a relatively long or short period of leave is the best option. In turn, there is the question of who is considered when determining the optimal length of leave: i.e. is it infants, mothers, fathers, or perhaps employers or taxpayers? 
- the level of payment is relatively generous; and

- fathers are actively encouraged to take a period of leave.

Hence, where mothers do not return to paid work, there is less incentive for fathers to take a period of leave. In addition, if mothers do not resume employment, fathers are less likely to experience a period of sole care of the child. However, childcare policies also affect these decisions. For example, in Sweden there is little taxpayer support for childcare for children under one year old. In contrast, in New Zealand childcare for children younger than 12 months is subsidised.

\section{An optimal length of leave?}

A review article published by the authors of this article in the Journal of Family Issues in 2005 considered whether there was an optimal length of leave. It seems that a short period of leave following childbirth is less costly to most employees in terms of its economic and employment effects. However, the negative economic consequences of longer leave appear to be less observable in countries like Sweden, where such behaviour is more predictable. Conversely, other research, mainly from the biomedical arena, suggests that longer and, ideally, paid parental leave periods are required if the highest attainable levels of child health are to be achieved. With regard to foetal and maternal health, leave policies must include measures that offer pregnant workers the opportunity to take a period of their leave entitlement prior to childbirth. However, taking a portion of leave in the pre-birth period should not, ideally, reduce the length of leave available to women following childbirth. In the prenatal period, however, it is difficult to determine a universally appropriate length of leave, as this is largely determined by the nature of the pregnancy, as well as the woman's job type and working conditions. Following childbirth, women's physical and mental health is generally facilitated by a period of leave. Moreover, research establishing the importance of a period of time out of the workplace to support longer periods of breastfeeding justifies on both public health and equal employment opportunity grounds the need for a six-month period of postnatal leave so that mothers

Table 2: Diverse goals relating to the design of parental leave policy

\begin{tabular}{|c|c|c|}
\hline Policy areas & Some of the issues to consider & Possible design of paid parental leave \\
\hline Health & $\begin{array}{l}\text { Mother's well-being in pregnancy, } \\
\text { birth and recovery; breastfeeding; } \\
\text { health problems related to group } \\
\text { childcare }\end{array}$ & $\begin{array}{l}\text { Paid leave not linked to job } \\
\text { protection but universal payment; } \\
\text { relatively long periods of leave; no } \\
\text { taxpayer support for out-of-home } \\
\text { childcare in the first year of child's life }\end{array}$ \\
\hline Employment & $\begin{array}{l}\text { Cost of time out of the workplace } \\
\text { for parents; problems faced by } \\
\text { employers with employees taking } \\
\text { leave; increasing non-standard work } \\
\text { affecting eligibility criteria }\end{array}$ & $\begin{array}{l}\text { Paid leave linked to job protection; } \\
\text { relatively short leave periods }\end{array}$ \\
\hline Gender equity & $\begin{array}{l}\text { Inequality in the workplace; roles } \\
\text { of mothers and fathers in the home; } \\
\text { differing family types (same-sex } \\
\text { couples, etc) }\end{array}$ & $\begin{array}{l}\text { Short gender-specific leave or longer } \\
\text { gender-neutral leave; specific 'daddy' } \\
\text { leave; promote leave-taking by fathers }\end{array}$ \\
\hline Supporting fertility & $\begin{array}{l}\text { Higher opportunity costs associated } \\
\text { with taking leave for well-educated } \\
\text { women }\end{array}$ & $\begin{array}{l}\text { High level of leave payment; } \\
\text { universal payment }\end{array}$ \\
\hline
\end{tabular}


can exclusively breastfeed their infants for this recommended period. ${ }^{9}$ In addition, workplace measures are required to enable those employees who wish, or are economically compelled, to return to work immediately following childbirth to better integrate their work and family commitments. These include measures for 'phasing back' through part-time work, shorter working days and/or flexitime, as well as provisions for breastfeeding breaks and facilities. Such measures are also required to enable employees returning to work after a period of leave to continue breastfeeding.

However, if an initial, six-month period of leave following childbirth is warranted primarily on maternal and child health grounds, leave then comes to be seen as unavoidably female-specific: i.e. pertaining primarily to women. Herein lies the gender equity conundrum. In heterosexual, two-parent families, if greater equality in both the home and the workplace is to be achieved, parental leave needs to be shared equally by both parents, thereby avoiding the entrenchment of traditional gendered roles and responsibilities. This then necessitates parents taking leave concurrently or, alternatively, an even longer period of leave, so that they can then take it consecutively. Leave longer than six months would ensure that fathers have the opportunity, and are also actively encouraged through education and policy measures, to both spend time with their child and balance the breastfeeding mother's potential time input during the early months, if indeed she takes leave for this purpose.

One way of achieving this scenario would be to emulate the Swedish model. Although still having a considerable way to go with regard to attaining full gender equality, Sweden has nevertheless managed to design and develop a parental leave policy package that recognises and endeavours to address the dual objectives of child health and gender equity.

\section{Conclusion}

Since 1999 New Zealand has had a taxpayer-funded, paid parental leave scheme, first as a tax credit, then as a cash payment to eligible parents. However, debate continues about the length of leave and the eligibility

9 The World Health Organization recommends a period of six months exclusive breastfeeding and partial breastfeeding up to two years and beyond. criteria, particularly given that the current New Zealand policy is less generous than those in some other OECD countries, notably the Nordic countries.

Given that there are many potential goals of paid parental leave, some of them conflicting, designing an optimal scheme in a New Zealand context is likely to remain a difficult public policy challenge. New Zealand's leave policy appears to have been designed as a compromise by the coalition government. Since it was introduced it has been altered a number of times, including through extensions to the length of leave and a loosening of its eligibility criteria. However, there still remains a fundamental question as to whether paid leave should be linked to job protection. We suggest that there is a need to keep the job protection legislation, but, primarily on health grounds, payment for leave either should be made available to all new parents or it should be targeted on income grounds. If the length of leave continues to increase it is likely that the question of how fathers are treated will also continue to be raised. While it seems doubtful that New Zealand will go as far as Sweden in setting aside a specific period of leave for fathers, we suggest there are good reasons to make at least part of the current period of paid leave for biological parents equally available to mothers and fathers, rather than giving primary eligibility to mothers.

Paul Callister is a Senior Research Fellow in the Institute of Policy Studies. His main research interests lie in the broad area of social policy and include issues relating to ethnicity, work-life balance, parental leave, migration patterns and labour market behaviour.

Judith Galtry completed a PhD in 2000 examining the interrelationship between employment policy and breastfeeding practice in New Zealand, Sweden and the USA. In recent years she has worked for a variety of agencies, including the Human Rights Commission as a policy analyst, the World Health Organization, Cornell University as a Research Fellow, and the Cancer Society of New Zealand. 


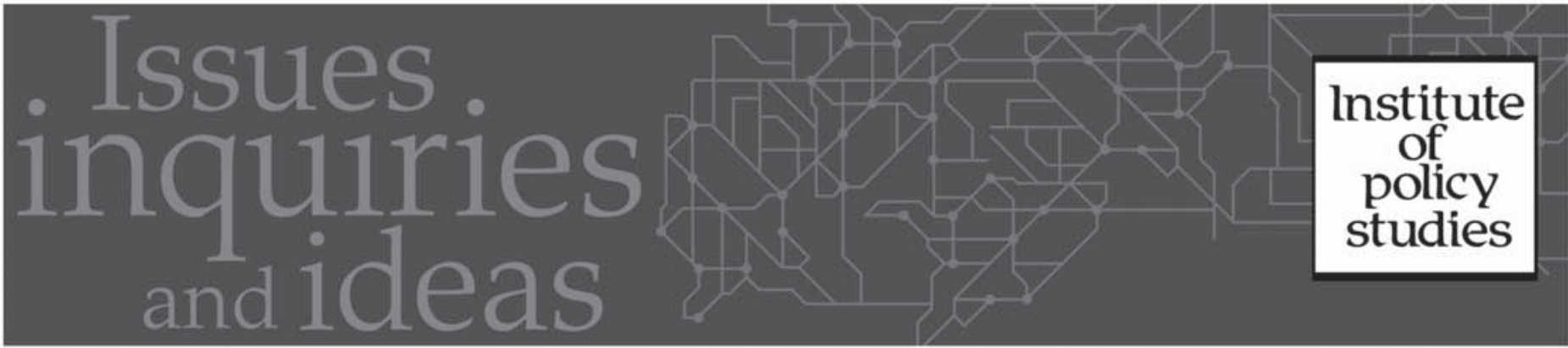

\title{
The Institute of Policy Studies School of Government
}

invites you to the launch of

\section{The Policy Implications of Diversity}

by

Jonathan Boston, Paul Callister and Amanda Wolf

\author{
Monday 6 March at 5pm \\ Mezzanine Floor \\ Rutherford House, Pipitea Campus, Bunny Street
}

\begin{abstract}
About the Book
Diversity matters. It furnishes the texture and variety of social life, thereby extending choice and opportunity. It can be a source of economic strength, cultural vitality, national pride and solidarity. But it can equally generate social conflict, ethnic tension and political instability - as witnessed, tragically, in many parts of the world, including the South Pacific.

This study, by three academics within the School of Government at Victoria University of Wellington, explores the various dimensions of diversity - its nature, meaning, measurement, ethical significance and policy implications. As New Zealand becomes increasingly diverse socially and culturally, the policy consequences - whether in terms of design, implementation or outcome - need to be carefully assessed and appropriately debated. This book provides an important contribution to that process.
\end{abstract}

RSVP to Barbara.Gillespie@vuw.ac.nz by Thursday 2 March 2006

\section{Victoria \\ UNIVERSITY OF WELLINGTON \\ Te Whare Wānanga \\ o te Ûpoko o te Ika a Māui

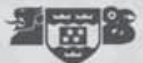

